\title{
Estimation of Pesticide Residues on Leafy Vegetables Using a Developed Handheld Spectrometer
}

\author{
Viet-Duc Ngo ${ }^{1,2, * \mathbb{D}}$, Le-Tuan-Anh Hoang ${ }^{1,2 \mathbb{D}}$, Van-Cong Pham ${ }^{2 \mathbb{C}}$, Van-Hieu Ngo ${ }^{2 \mathbb{C}}$, \\ Phuong-Ha Tran ${ }^{3}$ iD \\ 1 Graduate University of Science and Technology, Vietnam Academy of Science and Technology, Hanoi, Vietnam; \\ ngovietduc.cretech@gmail.com (V.-D.N.); \\ 2 Center for Research and Technology Transfer, Vietnam Academy of Science and Technology, Hanoi, Vietnam; \\ ngovietduc.cretech@gmail.com （V.-D.N.); hoangletuananh.cretech@gmail.com (L.-T.-A.H.), \\ phamcong1990@gmail.com (V.-C.P.); ngohieu03041997@gmail.com (V.-H.N.); \\ 3 Mientrung Institute for Scientific Research, Vietnam Academy of Science and Technology, Hue, Vietnam; \\ tpha@misr.vast.vn (P.-H.T.); \\ * Correspondence: ngovietduc.cretech@gmail.com (V.-D.N);
}

Scopus Author ID 55883758600

Received: 14.10.2021; Revised: 16.11.2021; Accepted: 19.11.2021; Published: 9.12.2021

\begin{abstract}
In this study, a rapid and non-destructive detection model for pesticide residues on leafy vegetables was presented using a developed portable spectrometer. VIS/NIR spectra of three vegetable samples, including lettuce, oriental mustard, and bok choy, were analyzed at the range of $380-840 \mathrm{~nm}$. Stepwise multiple linear regression (SMLR) models were developed based on chemical reference measurements and the spectral information of the leaf samples after performing the pre-processing method. Furthermore, a data acquisition interface was developed by Matlab GUI. Results of SMLR procedure indicated good performance for detection of indoxacarb and chlorantraniliprole with $\mathrm{R}^{2} \geq$ 0.90. A fairly good model $\left(0.90>R^{2}>0.80\right)$ was obtained for carbendazim in lettuce, whereas a poor model was found for emamectin-benzoate with $\mathrm{R}^{2} \leq 0.80$. It was concluded that pesticide residues on leafy vegetables could be predicted using our developed handheld spectrometer. It can also be generalized for the prediction of other pesticide components in agricultural products.
\end{abstract}

Keywords: pesticide residues; handheld spectrometer; smlr; leafy vegetable.

(C) 2021 by the authors. This article is an open-access article distributed under the terms and conditions of the Creative Commons Attribution (CC BY) license (https://creativecommons.org/licenses/by/4.0/).

\section{Introduction}

Pesticides are widely used during the production and post-harvest treatment of agricultural products. However, human health and contamination of the environment have been affected by the increased use of chemical pesticides [1-4]. Pesticide residues in agricultural products have always been a matter of serious concern, especially when these products are consumed fresh such as lettuce, mustard, cabbage, and kale [5-7]. Headaches, nausea, cancer, reproductive harm, and endocrine disruption are short-term and chronic effects on human health when using pesticides regularly [8-10].

Recently, fruits and vegetables have been given a lot of attention in monitoring programs because of higher pesticide residue levels than other food groups, and most of them are eaten raw [11-13]. At least five portions of fruits and vegetables are encouraged to eat daily as suggested by the Pesticide Residues Committee in the UK [14-16]. Vegetables provide many essential vitamins and minerals of a balanced diet. Besides, epidemiological studies reported that healthy lives, including lower risks of cancer, cardiovascular diseases, and obesity 
were probably related to higher intakes of vegetables. However, pests and diseases infestation may affect the yield and quality of vegetables. Therefore, it necessitates using pesticides during the production and storage of vegetables. Pesticide use has increased over the years to effectively control a pest complex of vegetable crops due to rapid action and less human resources requirement $[17,18]$. However, the exceeding prescribed maximum residue limits (MLRs) of pesticide residues in harvested produce are caused by injudicious use of these compounds, which may pose serious health risks as some of the vegetables are eaten raw or undercooked.

Pesticide residue monitoring is the only tool to control the quantity of pesticides on food. For the past few decades, regulatory authorities in many countries have been setting up monitoring systems for agricultural products and the environment. The appropriate use of pesticides in terms of authorization and registration (application rates and pre-harvest intervals) and compliance with maximum residue limits are monitored closely [19,20]. Pesticide residue monitoring is also recognized as a significant aspect of initiatives to reduce potential hazards to human health [21-24]. MRLs encourage food safety by restricting the concentration of a residue permitted on a commodity and limiting the type of commodity on which it is allowed [25-28]. MRLs have been established based on good agricultural practices (GAP) data. MRLs must be limited toxicologically. Exceeded MRLs are strong indicators of violations of GAP $[29,30]$.

The advantages of optical methods allow rapid measurement on a large number of samples, remain intact and could be used for further analysis. Spectral reflectance in the visible and near-infrared region $(400-2500 \mathrm{~nm})$ has been identified as a popular method to sense localized factors relating to the soil and crop. Results from spectral reflectance measurements have been widely used in arable research to evaluate such factors as soil properties, crop characteristics, crop functional components [31-33].

Although pesticide residue estimation in agricultural products was reported in some studies recently, a fast and non-destructive method for estimating pesticide residues on leafy vegetables has not been reported, especially serious when consumed fresh. In addition, the application of a cheap portable spectrometer to estimate the quality and quantity of agricultural products needs to be investigated. Research related to the quantification of pesticide residues on leafy vegetables is limited. This research aims to apply a developed portable spectrometer for pesticide residue estimation on three fresh leafy vegetables. In addition, important wavelengths related to those pesticide components were also identified.

\section{Materials and Methods}

\subsection{Leaf samples preparation.}

Lettuce (Lactuca sativa L.), oriental mustard (Brassica juncea), and bok choy (Brassica rapa subsp. Chinensis) were collected from a market in Hanoi, Hue, and Ho Chi Minh City in Vietnam. Three mature, healthy leaves were harvested from each plant for spectral reflectance measurements and pesticide residue analyses. Spectral reflectance data were measured using the handheld spectrometer before being transferred to a chemical laboratory for pesticide residue analyses. The leaf spectral reflectance data were collected at 15 points on the blade area and averaged to represent each leaf spectral reflectance reported in our previous studies [3436]. 
Three insecticides (Indoxacarb, chlorantraniliprole, emamectin-benzoate), one fungicide (Carbendazim), and one plant growth hormone (Gibberellic acid) were tested, which have been commonly used on vegetables in Vietnam. The chemical structures of the pesticides are shown in Figure 1. Totally, 68 data points for each insecticide, 54 data points for fungicide, and 50 data points for plant growth hormone were obtained.<smiles>COC(=O)N(C(=O)N1CO[C@@]2(C(=O)OC)Cc3cc(Cl)ccc3C2=N1)c1ccc(OC(F)(F)F)cc1</smiles>

Indoxacarb<smiles>COC(=O)Nc1nc2ccccc2[nH]1</smiles><smiles>CNC(=O)c1cc(Cl)cc(C)c1NC(=O)c1cc(Br)nn1-c1ncccc1Cl</smiles>

Chlorantraniliprole

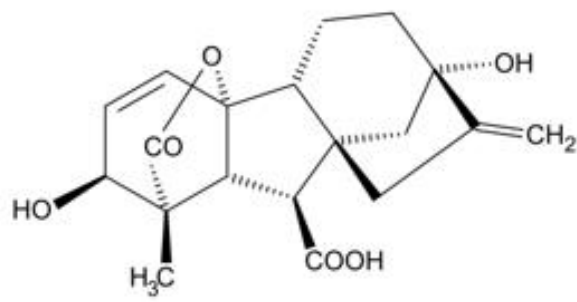

Gibberellic acid<smiles>[R][R4]Oc1ccccc1</smiles>

\section{Emamectin benzoate}

Figure 1. Chemical structures of pesticides used.

\subsection{Spectrometer characteristics.}

In this study, a Nanolambda application development kit (Model: NSP32m-W1 ADK, Nanolambda, Daejeon, South Korea), a full spectrum 1W LED, a rechargeable Li-ion battery was integrated to develop a portable spectrometer. The wavelength of LED was in the VIS 
region $(380-840 \mathrm{~nm})$. The data were transmitted to the computer via a USB port. The wavelength sensitivity of the sensor was in the range of $340-1000 \mathrm{~nm}$. Plasmonic filters are the core technology of Nanolambda's sensor. This sensor can be integrated onto a regular photodetector such as a complementary metal-oxide-semiconductor (CMOS) imager [37]. The spectral resolution was $1 \mathrm{~nm}$ and integration times were $100 \mathrm{~ms}$. The wavelength range of LED was $380-840 \mathrm{~nm}$ was used as an external light source.

Computed aided design and 3D printing was used for prototyping the enclosure to house the battery, spectrometer, and charging circuit. A rechargeable Li-ion battery with a nominal capacity of $400 \mathrm{mAh}$ and a nominal voltage of $3.7 \mathrm{~V}$ was supplied. A schematic diagram of the handheld spectrometer is described in Figure 2. Illumination of light source passed to the leaf sample, and the reflected light was detected by Nanolambda sensor. The header of the spectrometer was designed to measure reflectance in a dark condition to reduce the noise introduced by background effects and other uncertainties.
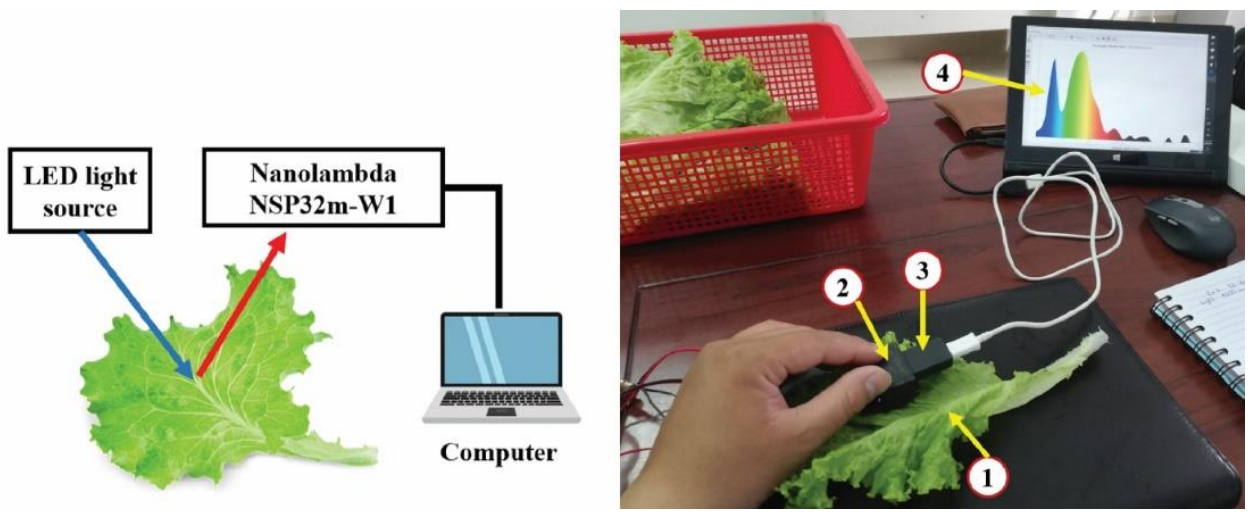

Figure 2. Schematic diagram of the spectral data acquisition system (1) lettuce leaf sample; (2) spectrometer holder; (3) spectrometer; (4) computer.
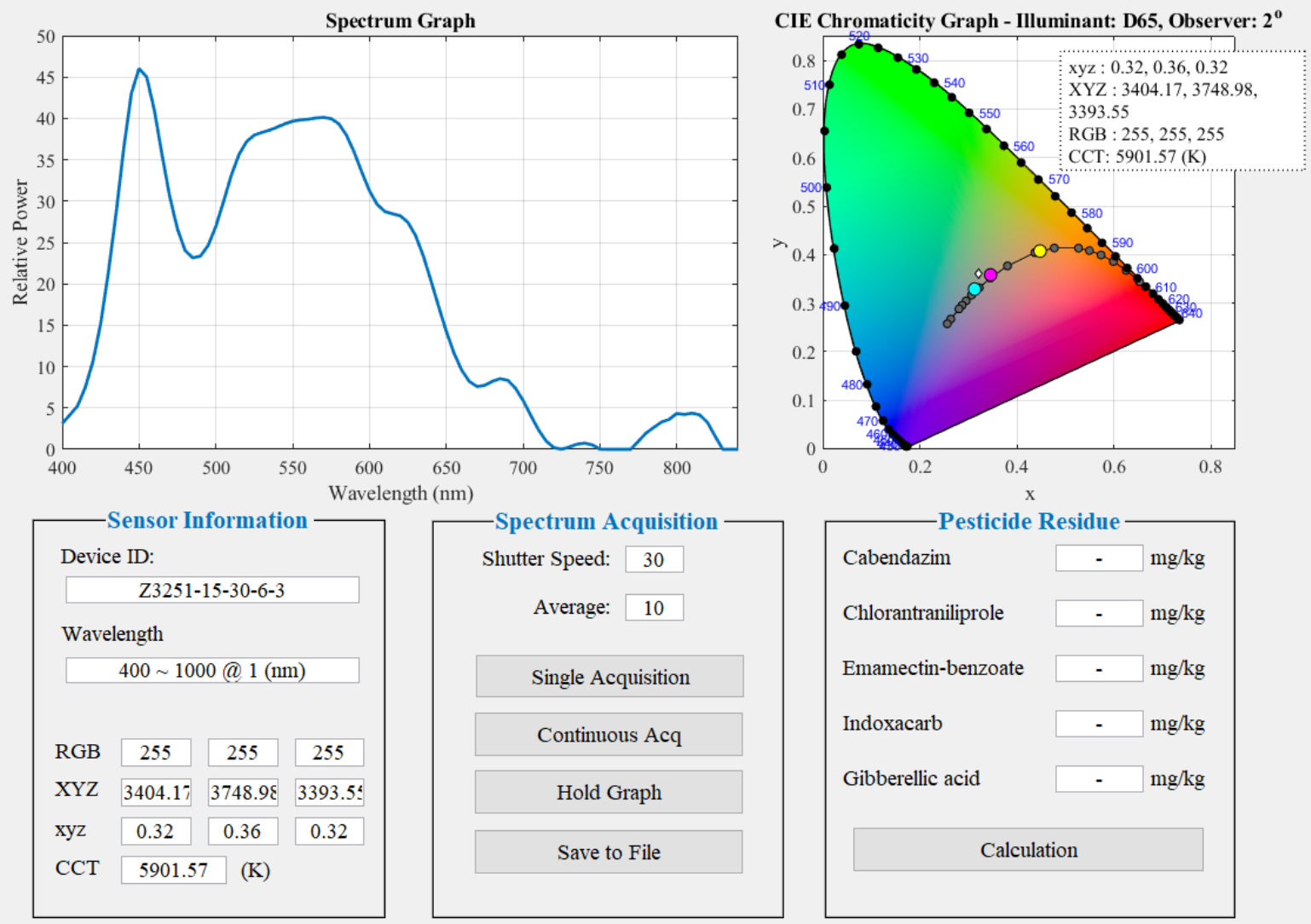

Figure 3. Data acquisition interface in Matlab GUI. 
A spectral data acquisition interface was developed by Matlab GUI, as depicted in Figure 3. To display the predicted value of the residue content, the best model developed for predicting the pesticide residue contents in the samples was displayed in the interface. Additionally, a CIE chromaticity graph of reflected light was also plotted for further study. Shutter speed and average spectra can adjust to obtain stable and more accurate spectral data.

\subsection{Spectrometer characteristics.}

To remove outliers and reach the actual spectra, the moving average method with 21 smoothing points was applied. After using the smoothing method, the mathematical transformation of pre-processed reflectance data was additionally performed to investigate the simple non-linear relationship between reflectance spectra and the pesticide residues. The used transformations were 1st and 2nd Savitzky-Golay (S. Golay) derivatives ( $\mathrm{d} \lambda$ and $2 \mathrm{~d} \lambda$ ), square $\operatorname{root}(\sqrt{ } \lambda)$, squared power $\left(\lambda^{2}\right)$, logarithm base $10(\log (\lambda))$, inversion $(1 / \lambda)$, and exponent $\left(\mathrm{e}^{\lambda}\right)$. Considering too many bands of spectral data is unnecessary. Therefore, stepwise multiple linear regression (SMLR) was employed to estimate pesticide residue concentration in the leaf. The adjusted coefficient of determination $\left(\operatorname{Adj}-\mathrm{R}^{2}\right)$ and root mean square error of prediction (RMSE) were computed and analyzed. All statistical analyses were conducted using Matlab (Ver. R2018a, The MathWorks, Natick, MA, USA) and displayed in the interface.

\section{Results and Discussion}

\subsection{Summary of the chemical analyses and reflectance spectrum.}

A summary of the descriptive statistics for the chemical determination of the pesticide residue content is provided in Table 1. Interestingly, pesticide residue contents were below the maximum residue limits. However, these components might affect human health when regularly exposed. The maximum residue limits (MRL) of the pesticides were established by FAO/WHO Codex Alimentarius. Mass spectrometry analysis demonstrated that gibberellic acid was below the determination limit $\left(<0.01 \mathrm{mg} \cdot \mathrm{kg}^{-1}\right)$. Therefore, in this study, gibberellic acid was ignored due to non-detection.

Table 1. Statistics of pesticide residue contents in the vegetable.

\begin{tabular}{|c|c|c|c|c|}
\hline Vegetable & Component & $\begin{array}{c}\text { No. of } \\
\text { sample }\end{array}$ & $\begin{array}{c}\text { Pesticide residue } \\
(\mathrm{mg} / \mathrm{kg})\end{array}$ & $\begin{array}{c}\text { MRL } \\
(\mathrm{mg} / \mathrm{kg})\end{array}$ \\
\hline Carbendazim (mg/kg) & Lettuce & 68 & $0.16 \pm 0.002$ & 5 \\
\hline \multirow{3}{*}{ Chlorantraniliprole $(\mathrm{mg} / \mathrm{kg})$} & Lettuce & \multirow[t]{3}{*}{68} & $0.18 \pm 0.01$ & \multirow[t]{3}{*}{20} \\
\hline & Oriental mustard & & $0.56 \pm 0.06$ & \\
\hline & Bok choy & & $0.25 \pm 0.03$ & \\
\hline Emamectin-benzoate $(\mathrm{mg} / \mathrm{kg})$ & Lettuce & 68 & $0.27 \pm 0.03$ & 0.7 \\
\hline \multirow{3}{*}{ Indoxacarb $(\mathrm{mg} / \mathrm{kg})$} & Lettuce & \multirow[t]{3}{*}{54} & $0.55 \pm 0.04$ & 7 \\
\hline & Oriental mustard & & $0.39 \pm 0.08$ & \\
\hline & Bok choy & & $0.48 \pm 0.06$ & \\
\hline \multirow[t]{3}{*}{ Gibberellic acid (mg/kg) } & Lettuce & \multirow[t]{3}{*}{50} & $\mathrm{BDL}^{1}$ & no specific \\
\hline & Oriental mustard & & BDL & \\
\hline & Bok choy & & BDL & \\
\hline
\end{tabular}

Figure 4 presents the pre-processed reflectance spectra of lettuce, oriental mustard, and bok choy using the handheld spectrometer. The results of the combination pre-processing method showed less noise compared with the raw data. In the NIR range $(700-840 \mathrm{~nm})$, oriental mustard showed a slightly greater reflectance than lettuce and bok choy, whereas the reflectance of oriental mustard was lower than the others in the VIS range $(380-700 \mathrm{~nm})$. The 
difference among the three varieties was not obvious after using the combination of moving average smoothing and derivative methods.
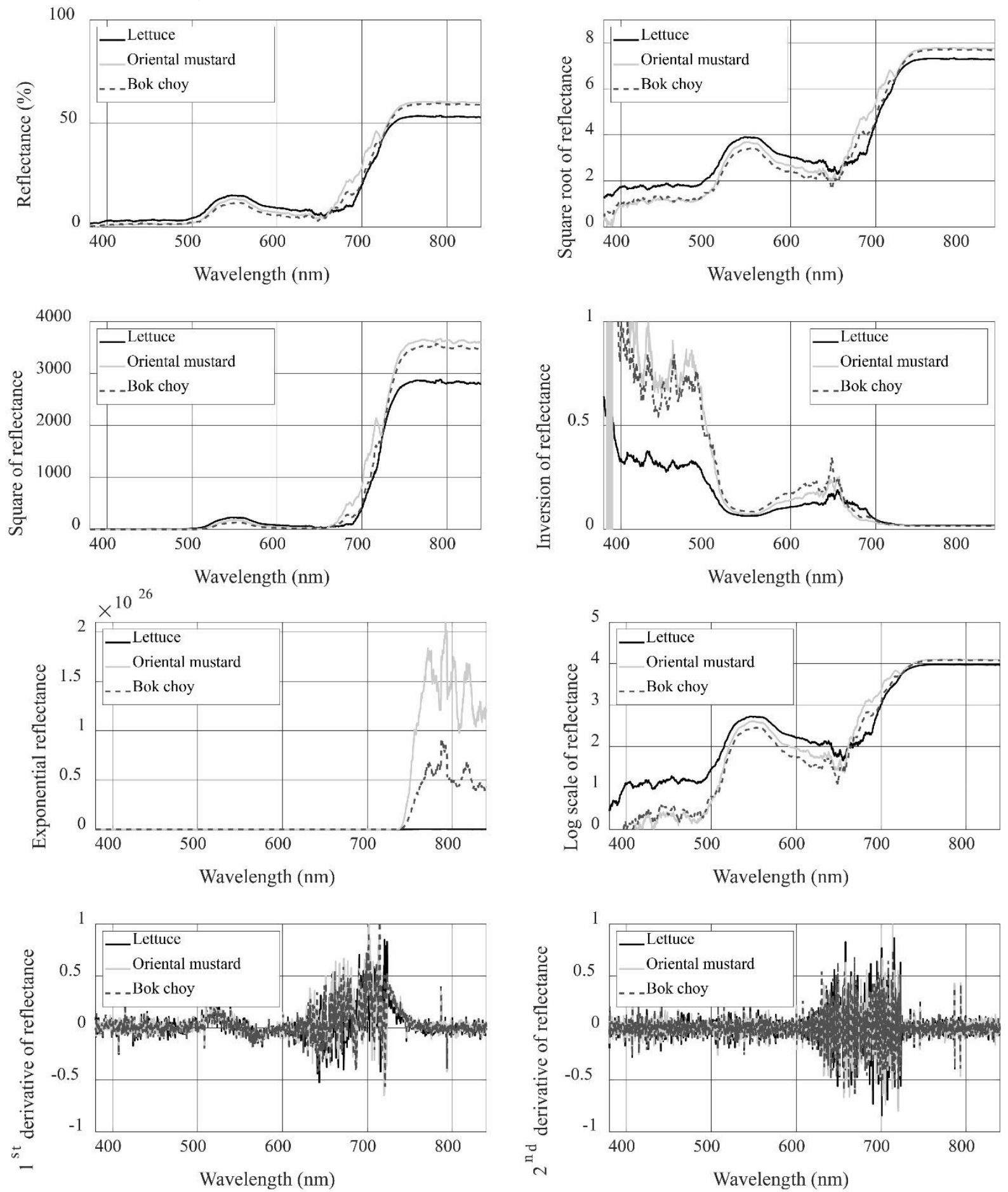

Figure 4. Pre-processed reflectance spectra using the combination of moving average smoothing and mathematical transformations.

\subsection{Estimation models of the pesticide residues.}

Pearson correlation coefficients between reflectance spectra and carbendazim are shown in Figure 5. Reflectance in the VIS range $(500-700 \mathrm{~nm})$ was highly correlated with pesticide residues. The absolute values of correlations were higher for some transformations (e.g., square power, exponent, and $1^{\text {st }} \mathrm{S}$. Golay derivative). Correlation between pesticide residues and $2^{\text {nd }} \mathrm{S}$. Golay derivative of spectral data was not conspicuous. 

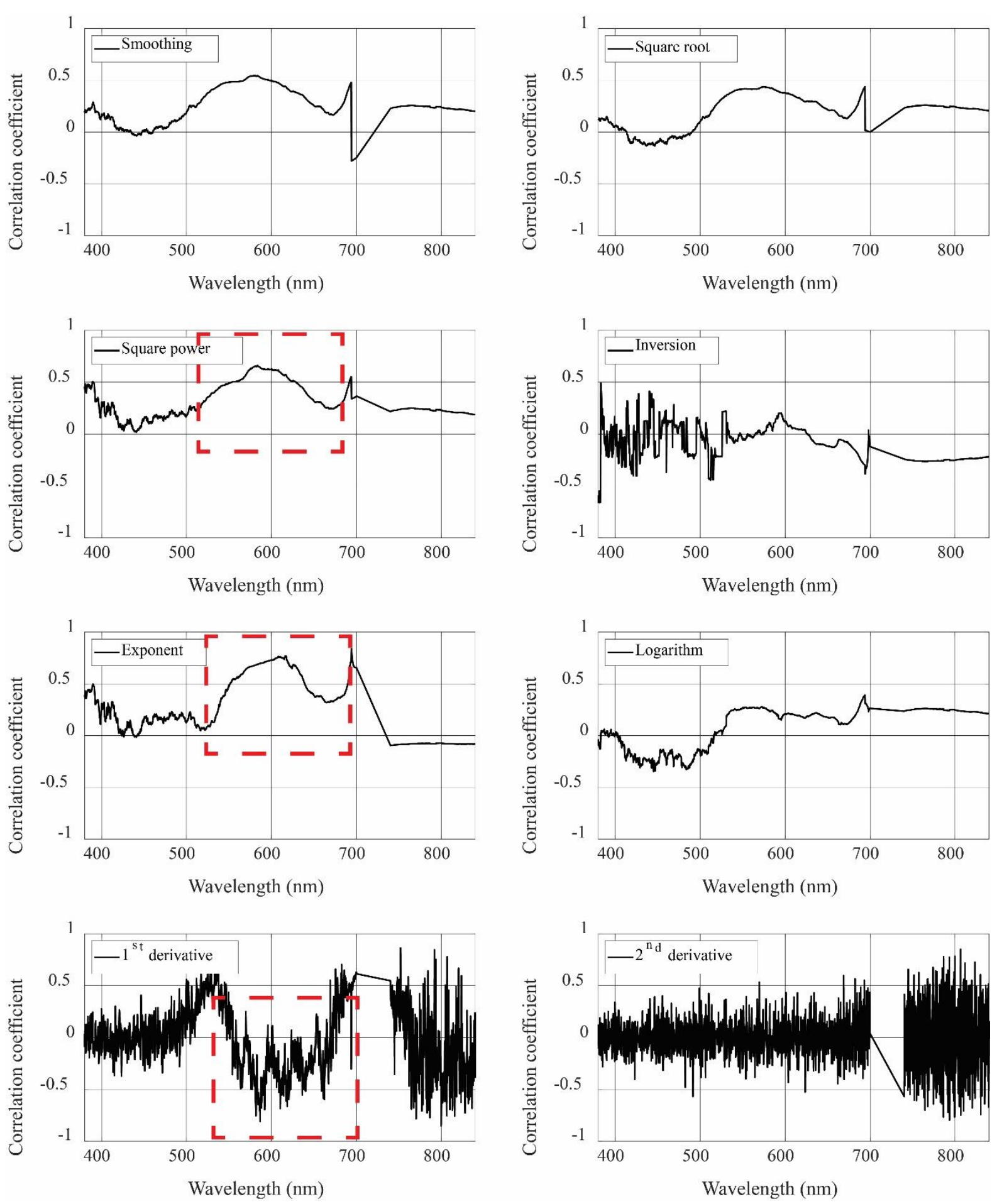

Figure 5. Correlation coefficients between pre-processed reflectance data and carbendazim.

Table 2 presents the results of the SMLR procedure over the wavelength range. The best model of the SMLR procedure was selected to estimate pesticide components. Good estimation models with $\mathrm{R}^{2} \geq 0.90$ were obtained for chlorantraniliprole in oriental mustard $\left(\mathrm{R}^{2}\right.$ $=0.93)$ and bok choy $\left(\mathrm{R}^{2}=0.92\right)$; indoxacarb in lettuce $\left(\mathrm{R}^{2}=0.96\right)$ and bok choy $\left(\mathrm{R}^{2}=0.98\right)$. Fairly good models $\left(\mathrm{R}^{2}=0.80-0.90\right)$ were found for carbendazim and chlorantraniliprole in lettuce $\left(R^{2}=0.86\right)$, and indoxacarb in oriental mustard $\left(R^{2}=0.88\right)$. However, the result of the SMLR was poor $\left(R^{2} \leq 0.80\right)$ for emamectin-benzoate. The selected wavelengths of $\lambda, d \lambda, 2 d \lambda$, and $\lambda^{2}$ were slightly different in the same pesticide component, but various apparently in different components. 
Table 2. Results of SMLR procedures over the entire spectral region $(380-840 \mathrm{~nm})$.

\begin{tabular}{|c|c|c|c|c|c|}
\hline Pesticide component & Variety & Transformation & Adj-R ${ }^{2}$ & RMSE & Selected wavelength $(\mathrm{nm})$ \\
\hline Carbendazim (mg/kg) & Lettuce & $2 \mathrm{~d} \lambda$ & 0.86 & 2.11 & $\begin{array}{l}482,530,589,623,751, \\
785,833\end{array}$ \\
\hline \multirow[t]{3}{*}{ Chlorantraniliprole (mg/kg) } & Lettuce & $\lambda$ & 0.86 & 0.33 & $\begin{array}{l}407,417,469,515,590, \\
616,659,672,681,691\end{array}$ \\
\hline & $\begin{array}{l}\text { Oriental } \\
\text { mustard }\end{array}$ & $\mathrm{d} \lambda$ & 0.93 & 0.23 & $\begin{array}{l}497,660,678,686,742, \\
782,806,810,823\end{array}$ \\
\hline & Bok choy & $2 \mathrm{~d} \lambda$ & 0.92 & 0.25 & $\begin{array}{l}384,484,490,529,567, \\
590,755,766,812,819,822\end{array}$ \\
\hline Emamectin-benzoate $(\mathrm{mg} / \mathrm{kg})$ & Lettuce & $\mathrm{d} \lambda$ & 0.79 & 0.88 & $401,541,669,757,763,787$ \\
\hline \multirow[t]{3}{*}{ Indoxacarb $(\mathrm{mg} / \mathrm{kg})$} & Lettuce & $\lambda$ & 0.96 & 0.17 & $\begin{array}{l}403,475,476,490,496, \\
535,576,583,590,592, \\
604,694\end{array}$ \\
\hline & $\begin{array}{l}\text { Oriental } \\
\text { mustard }\end{array}$ & $\lambda^{2}$ & 0.88 & 0.29 & 583,590 \\
\hline & Bok choy & $2 \mathrm{~d} \lambda$ & 0.98 & 0.12 & $\begin{array}{l}390,436,445,498,538, \\
562,579,655,693,756, \\
781,788,806\end{array}$ \\
\hline
\end{tabular}

Literature reported that the spectra of sedimented carbendazim were recorded in the range of $500-850 \mathrm{~nm}$ [38]. The maximum absorption spectra of sedimented carbendazim occurred at $685 \mathrm{~nm}$, and the absorbance at this wavelength was increased upon increasing carbendazim concentration. In a study by Strickland and Batt [39], a pesticide detection method was presented using cyclodextrin-based complexation and surface-enhance Raman scattering (SERS) on gold nanorods. The result showed the $785 \mathrm{~nm}$ laser excitation used in the SERS studies. The wavelength was also reported in our model. It proved that the wavelength $785 \mathrm{~nm}$ was significant. For chlorantraniliprole, wavelengths around the red edge $(680-750 \mathrm{~nm})$ and NIR regions $(750-840 \mathrm{~nm})$ were identified by the SMLR model. These regions were reported as absorption regions of chlorophyll and carotenoid [40-44]. Wavelengths at 401, 541, 669, 757, 763, and $787 \mathrm{~nm}$ were determined by the SMLR model for emamectin-benzoate, while the wavelengths at 403, 475, 476, 490, 496, 535, 576, 583, 590, 592, 604, and $694 \mathrm{~nm}$ had a strong correlation with indoxacarb in lettuce. It was also found that the selected wavelengths by the SMLR procedure for indoxacarb in oriental mustard were around the yellow region (570 $-590 \mathrm{~nm}$ ). Yalçın et al. [45] used the wavelength at $590 \mathrm{~nm}$ to investigate the resistance of two populations of $T$. absoluta against five commonly used insecticides (indoxacarb, chlorantraniliprole, metaflumizone, spinosad, and azadirachtin). Additionally, $590 \mathrm{~nm}$ was also used to determine the susceptibility and esterase activity of the $3^{\text {rd }}$ and $5^{\text {th }}$ instar larva of Spodoptera litura against three insecticides, including carbamates and chlorantraniliprole, in a study by Muthusamy et al. [46].

\section{Conclusions}

The present study results indicate that the content of pesticide residues in leafy vegetables can be predicted using the optical spectrum data in the VIS-NIR region $(380-840$ $\mathrm{nm}$ ) by the SMLR procedure. A cheap portable spectrometer developed for spectral data acquisition was useful. To produce accurate results, a smoothing method and mathematical transformation of collecting spectral datasets were applied. The results showed that chlorantraniliprole and indoxacarb were highly estimated with adj- $\mathrm{R}^{2} \geq 0.90$. The good performance of the SMLR method was observed for indoxacarb in bok choy leaf. Important wavelengths for estimating pesticide residues were laid around red-edge and NIR regions assigned to pigment absorption, such as carotenoid and chlorophyll. The violet region (380 $450 \mathrm{~nm}$ ) was associated with the pesticide component for lettuce. A wavelength of $590 \mathrm{~nm}$ was 
reported as an important wavelength for developing prediction models of chlorantraniliprole and indoxacarb. The findings of this study would be useful for designing or developing any multiple wavelength spectrometer for pesticide residues determination of any crops.

\section{Funding}

This research is funded by the Graduate University of Science and Technology under grant number GUST.STS.DT2018-CH01.

\section{Acknowledgments}

This work was supported by Mientrung Institute for Scientific Research; Center for Research and Technology Transfer, Vietnam Academy of Science and Technology (VAST); and Ton Duc Thang University, Ho Chi Minh City, Vietnam

\section{Conflicts of Interest}

The authors declare no conflict of interest.

\section{References}

1. Jacquet, F.; Butault, J.-P.; Guichard, L. An Economic Analysis of the Possibility of Reducing Pesticides in French Field Crops. Ecological Economics 2011, 70, 1638-1648, https://doi.org/10.1016/j.ecolecon.2011.04.003.

2. Yigit, N.; Velioglu, Y. S. Effects of Processing and Storage on Pesticide Residues in Foods. Critical Reviews in Food Science and Nutrition 2020, 60, 3622-3641, https://doi.org/10.1080/10408398.2019.1702501.

3. Li, C.; Zhu, H.; Li, C.; Qian, H.; Yao, W.; Guo, Y. The Present Situation of Pesticide Residues in China and Their Removal and Transformation during Food Processing. Food Chemistry 2021, 354, 129552, https://doi.org/10.1016/j.foodchem.2021.129552.

4. Bhandari, G.; Atreya, K.; Scheepers, P. T. J.; Geissen, V. Concentration and Distribution of Pesticide Residues in Soil: Non-Dietary Human Health Risk Assessment. Chemosphere 2020, 253, 126594, https://doi.org/10.1016/j.chemosphere.2020.126594.

5. El-Nahhal, I.; El-Nahhal, Y. Pesticide Residues in Drinking Water, Their Potential Risk to Human Health and Removal Options. Journal of Environmental Management 2021, 299, 113611, https://doi.org/10.1016/j.jenvman.2021.113611.

6. Wu, P.; Wang, P.; Gu, M.; Xue, J.; Wu, X. Human Health Risk Assessment of Pesticide Residues in Honeysuckle Samples from Different Planting Bases in China. Science of The Total Environment 2021, 759, 142747, https://doi.org/10.1016/j.scitotenv.2020.142747.

7. El-Nahhal, Y. Pesticide Residues in Honey and Their Potential Reproductive Toxicity. Science of The Total Environment 2020, 741, 139953, https://doi.org/10.1016/j.scitotenv.2020.139953.

8. Cooper, J.; Dobson, H. The Benefits of Pesticides to Mankind and the Environment. Crop Protection 2007, 26 (9), 1337-1348, https://doi.org/10.1016/j.cropro.2007.03.022.

9. Lamichhane, J. R.; Dachbrodt-Saaydeh, S.; Kudsk, P.; Messéan, A. Toward a Reduced Reliance on Conventional Pesticides in European Agriculture. Plant Disease 2016, 100, 10-24, https://doi.org/10.1094/PDIS-05-15-0574-FE.

10. Abd-Elhaleem, Z. A. Pesticide Residues in Tomato and Tomato Products Marketed in Majmaah Province, KSA, and Their Impact on Human Health. Environ Sci Pollut Res 2020, 27, 8526-8534, https://doi.org/10.1007/s11356-019-07573-X.

11. Al-Nasir, F. M.; Jiries, A. G.; Al-Rabadi, G. J.; Alu'datt, M. H.; Tranchant, C. C.; Al-Dalain, S. A.; Alrabadi, N.; Madanat, O. Y.; Al-Dmour, R. S. Determination of Pesticide Residues in Selected Citrus Fruits and Vegetables Cultivated in the Jordan Valley. LWT 2020, 123, 109005, https://doi.org/10.1016/j.lwt.2019.109005.

12. Golge, O.; Cinpolat, S.; Kabak, B. Quantification of Pesticide Residues in Gherkins by Liquid and Gas Chromatography Coupled to Tandem Mass Spectrometry. Journal of Food Composition and Analysis 2021, 96, 103755, https://doi.org/10.1016/j.jfca.2020.103755.

13. Medina, M. B.; Munitz, M. S.; Resnik, S. L. Effect of Household Rice Cooking on Pesticide Residues. Food Chemistry 2021, 342, 128311, https://doi.org/10.1016/j.foodchem.2020.128311. 
14. Jankuloska, V.; Karov, I.; Pavlovska, G.; Kalevska, T.; Stamatovska, V.; Uzunoska, Z. PESTICIDE RESIDUES IN FOOD: FOOD SAFETY, NUTRITION AND HEALTH EFFECTS. International Journal of Food Technology and Nutrition 2019, 2 , 36-41, https://eprints.unite.edu.mk/378/.

15. Seo, Y.-H.; Cho, T.-H.; Hong, C.-K.; Kim, M.-S.; Cho, S.-J.; Park, W.-H.; Hwang, I.-S.; Kim, M.-S. Monitoring and Risk Assessment of Pesticide Residues in Commercially Dried Vegetables. Prev Nutr Food Sci 2013, 18, 145-149, https://doi.org/10.3746/pnf.2013.18.2.145.

16. Nehra, M.; Dilbaghi, N.; Marrazza, G.; Kaushik, A.; Sonne, C.; Kim, K.-H.; Kumar, S. Emerging Nanobiotechnology in Agriculture for the Management of Pesticide Residues. Journal of Hazardous Materials 2021, 401, 123369, https://doi.org/10.1016/j.jhazmat.2020.123369.

17. Li, W.; Tai, L.; Liu, J.; Gai, Z.; Ding, G. Monitoring of Pesticide Residues Levels in Fresh Vegetable Form Heibei Province, North China. Environ Monit Assess 2014, 186, 6341-6349, https://doi.org/10.1007/s10661014-3858-7.

18. Mac Loughlin, T. M.; Peluso, Ma. L.; Etchegoyen, Ma. A.; Alonso, L. L.; de Castro, Ma. C.; Percudani, Ma. C.; Marino, D. J. G. Pesticide Residues in Fruits and Vegetables of the Argentine Domestic Market: Occurrence and Quality. Food Control 2018, 93, 129-138, https://doi.org/10.1016/j.foodcont.2018.05.041.

19. Fosu, P. O.; Donkor, A.; Ziwu, C.; Dubey, B.; Kingsford-Adaboh, R.; Asante, I.; Nyarko, S.; Tawiah, R.; Nazzah, N. Surveillance of Pesticide Residues in Fruits and Vegetables from Accra Metropolis Markets, Ghana, 2010-2012: A Case Study in Sub-Saharan Africa. Environ Sci Pollut Res 2017, 24, 17187-17205, https://doi.org/10.1007/s11356-017-9287-8.

20. Łozowicka, B.; Kaczyński, P.; Jankowska, M.; Rutkowska, E.; Hrynko, I. Pesticide Residues in Raspberries (Rubus Idaeus L.) and Dietary Risk Assessment. null 2012, 5, 165-171, https://doi.org/10.1080/19393210.2012.681398.

21. Damalas, C. A.; Eleftherohorinos, I. G. Pesticide Exposure, Safety Issues, and Risk Assessment Indicators. International Journal of Environmental Research and Public Health 2011, 8, 1402-1419, https://doi.org/10.3390/ijerph8051402.

22. Damalas, C. A.; Koutroubas, S. D. Farmers' Training on Pesticide Use Is Associated with Elevated Safety Behavior. Toxics 2017, 5, 19, https://doi.org/10.3390/toxics5030019.

23. Feng, J.; Tang, H.; Chen, D.; Li, L. Monitoring and Risk Assessment of Pesticide Residues in Tea Samples from China. Human and Ecological Risk Assessment: An International Journal 2015, 21, 169-183, https://doi.org/10.1080/10807039.2014.894443.

24. Valcke, M.; Bourgault, M.-H.; Rochette, L.; Normandin, L.; Samuel, O.; Belleville, D.; Blanchet, C.; Phaneuf, D. Human Health Risk Assessment on the Consumption of Fruits and Vegetables Containing Residual Pesticides: A Cancer and Non-Cancer Risk/Benefit Perspective. Environment International 2017, 108, 63-74, https://doi.org/10.1016/j.envint.2017.07.023.

25. Blasco, C.; Font, G.; Picó, Y. Evaluation of 10 Pesticide Residues in Oranges and Tangerines from Valencia (Spain). Food Control 2006, 17, 841-846, https://doi.org/10.1016/j.foodcont.2005.05.013.

26. Chen, C.; Qian, Y.; Chen, Q.; Tao, C.; Li, C.; Li, Y. Evaluation of Pesticide Residues in Fruits and Vegetables from Xiamen, China. Food Control 2011, 22, 1114-1120, https://doi.org/10.1016/j.foodcont.2011.01.007.

27. European Food Safety Authority. The 2014 European Union Report on Pesticide Residues in Food. EFSA Journal 2016, 14, e04611, https://doi.org/10.2903/j.efsa.2016.4611.

28. Ramadan, M. F. A.; Abdel-Hamid, M. M. A.; Altorgoman, M. M. F.; AlGaramah, H. A.; Alawi, M. A.; Shati, A. A.; Shweeta, H. A.; Awwad, N. S. Evaluation of Pesticide Residues in Vegetables from the Asir Region, Saudi Arabia. Molecules 2020, 25, 205, https://doi.org/10.3390/molecules25010205.

29. Gupta, P. K. CHAPTER 44 - WHO/FAO Guidelines for Cholinesterase-Inhibiting Pesticide Residues in Food. In Toxicology of Organophosphate \& Carbamate Compounds 2006, 643-654, https://doi.org/10.1016/B978-012088523-7/50045-4.

30. Leong, W.-H.; Teh, S.-Y.; Hossain, M. M.; Nadarajaw, T.; Zabidi-Hussin, Z.; Chin, S.-Y.; Lai, K.-S.; Lim, S.-H. E. Application, Monitoring and Adverse Effects in Pesticide Use: The Importance of Reinforcement of Good Agricultural Practices (GAPs). Journal of Environmental Management 2020, 260, 109987, https://doi.org/10.1016/j.jenvman.2019.109987.

31. Scotford, I. M.; Miller, P. C. H. Applications of Spectral Reflectance Techniques in Northern European Cereal Production: A Review. Biosystems Engineering 2005, 90, 235-250, https://doi.org/10.1016/j.biosystemseng.2004.11.010.

32. Mirghafouri, M. R.; Abbasi-Moayed, S.; Ghasemi, F.; Hormozi-Nezhad, M. R. Nanoplasmonic Sensor Array for the Detection and Discrimination of Pesticide Residues in Citrus Fruits. Anal. Methods 2020, 12, 58775884, https://doi.org/10.1039/D0AY02039G.

33. Chen, Y.; Liu, H.; Tian, Y.; Du, Y.; Ma, Y.; Zeng, S.; Gu, C.; Jiang, T.; Zhou, J. In Situ Recyclable SurfaceEnhanced Raman Scattering-Based Detection of Multicomponent Pesticide Residues on Fruits and Vegetables by the Flower-like MoS2@Ag Hybrid Substrate. ACS Appl. Mater. Interfaces 2020, 12, 1438614399, https://doi.org/10.1021/acsami.9b22725.

34. Chung, S.-O.; Ngo, V.-D.; Kabir, M. S. N.; Hong, S.-J.; Park, S.-U.; Kim, S.-J.; Park, J.-T. Number of Sampling Leaves for Reflectance Measurement of Chinese Cabbage and Kale. Korean Journal of Agricultural Science 2014, 41, 169-175, https://doi.org/10.7744/cnujas.2014.41.3.169. 
35. Ngo, V.-D.; Chung, S.-O.; Park, S.-U.; Kim, S.-J.; Park, J.-T.; Kim, Y.-J. Determination of the Sample Number for Optical Reflectance Measurement of Vegetable Leaf. Computers and Electronics in Agriculture 2015, 112, 110-115, https://doi.org/10.1016/j.compag.2015.01.004.

36. Ngo, V.-D.; Kang, S.-W.; Ryu, D.-K.; Chung, S.-O.; Park, S.-U.; Kim, S.-J.; Park, J.-T. Location of Sampling Points in Optical Reflectance Measurements of Chinese Cabbage and Kale Leaves. Journal of Biosystems Engineering 2015, 40, 115-123, https://doi.org/10.5307/JBE.2015.40.2.115.

37. Chang, C.-C.; Wu, C.-T.; Choi, B. I.; Fang, T.-J. MW-PPG Sensor: An on-Chip Spectrometer Approach. Sensors 2019, 19, 3698, https://doi.org/10.3390/s19173698.

38. Pourreza, N.; Rastegarzadeh, S.; Larki, A. Determination of Fungicide Carbendazim in Water and Soil Samples Using Dispersive Liquid-Liquid Microextraction and Microvolume UV-Vis Spectrophotometry. Talanta 2015, 134, 24-29, https://doi.org/10.1016/j.talanta.2014.10.056.

39. Strickland, A. D.; Batt, C. A. Detection of Carbendazim by Surface-Enhanced Raman Scattering Using Cyclodextrin Inclusion Complexes on Gold Nanorods. Anal. Chem. 2009, 81, 2895-2903, https://doi.org/10.1021/ac801626x.

40. Gitelson, A. A.; Merzlyak, M. N.; Chivkunova, O. B. Optical Properties and Nondestructive Estimation of Anthocyanin Content in Plant LeavesII. Photochemistry and Photobiology 2007, 74, 38-45, https://doi.org/10.1562/0031-8655(2001)0740038OPANEO2.0.CO2.

41. Guanter, L.; Rossini, M.; Colombo, R.; Meroni, M.; Frankenberg, C.; Lee, J.-E.; Joiner, J. Using Field Spectroscopy to Assess the Potential of Statistical Approaches for the Retrieval of Sun-Induced Chlorophyll Fluorescence from Ground and Space. Remote Sensing of Environment 2013, 133, 52-61, https://doi.org/10.1016/j.rse.2013.01.017.

42. Martínez-Valdivieso, D.; Font, R.; Blanco-Díaz, M. T.; Moreno-Rojas, J. M.; Gómez, P.; Alonso-Moraga, Á.; Del Río-Celestino, M. Application of Near-Infrared Reflectance Spectroscopy for Predicting Carotenoid Content in Summer Squash Fruit. Computers and Electronics in Agriculture 2014, 108, 71-79, https://doi.org/10.1016/j.compag.2014.07.003.

43. Ošt’ádalová, M.; Tremlová, B.; Pokorná, J.; Král, M. Chlorophyll as an Indicator of Green Tea Quality. Acta Vet. Brno 2015, 83, 103-109, https://doi.org/10.2754/avb201483S10S103.

44. Zhang, P.; Wei, Y.; Xu, F.; Wang, H.; Chen, M.; Shao, X. Changes in the Chlorophyll Absorbance Index (IAD) Are Related to Peach Fruit Maturity. New Zealand Journal of Crop and Horticultural Science 2020, 48, 34-46, https://doi.org/10.1080/01140671.2019.1664598.

45. Yalçın, M.; Mermer, S.; Kozacı, L. D.; Turgut, C. Insecticide Resistance in Two Populations of Tuta Absoluta (Meyrick, 1917) (Lepidoptera: Gelechiidae) from Turkey. Turkish Journal of Entomology 2015, 39, 137-145, https://doi.org/10.16970/ted.63047.

46. Muthusamy, R.; Vishnupriya, M.; Shivakumar, M. S. Biochemical Mechanism of Chlorantraniliprole Resistance in Spodoptera Litura (Fab) (Lepidoptera: Noctuidae). Journal of Asia-Pacific Entomology 2014, 17, 865-869, https://doi.org/10.1016/j.aspen.2014.09.001. 